\title{
Evaluation of a Specialized Yoga Program for Persons Admitted to a Complex Continuing Care Hospital: A Pilot Study
}

\author{
Kathryn Curtis, ${ }^{1}$ Kerry Kuluski, ${ }^{2,3}$ Gitte Bechsgaard, ${ }^{4}$ Jennifer Ridgway, ${ }^{5}$ and Joel Katz \\ ${ }^{1}$ Department of Psychology, Faculty of Health, York University, 4700 Keele St., Toronto, ON, Canada M3J 1P3 \\ ${ }^{2}$ Lunenfeld-Tanenbaum Research Institute, Sinai Health System, 982-600 University Avenue, Toronto, ON, Canada M5G 1 X5 \\ ${ }^{3}$ Institute of Health Policy, Management and Evaluation, University of Toronto, 4th Floor, 155 College St., Toronto, ON, \\ Canada M5T $3 M 6$ \\ ${ }^{4}$ Vidya Institute, 253 Christie St., Toronto, ON, Canada M6G $3 B 8$ \\ ${ }^{5}$ Therapeutic Recreation, Sinai Health System-Bridgepoint Site, 1 Bridgepoint Drive, Toronto, ON, Canada M4M $2 B 5$ \\ Correspondence should be addressed to Kathryn Curtis; kjbc@yorku.ca
}

Received 27 May 2016; Revised 7 October 2016; Accepted 7 November 2016

Academic Editor: Bangalore N. Gangadhar

Copyright (C) 2016 Kathryn Curtis et al. This is an open access article distributed under the Creative Commons Attribution License, which permits unrestricted use, distribution, and reproduction in any medium, provided the original work is properly cited.

\begin{abstract}
Introduction. The purpose of this study was to evaluate a specialized yoga intervention for inpatients in a rehabilitation and complex continuing care hospital. Design. Single-cohort repeated measures design. Methods. Participants $(N=10)$ admitted to a rehabilitation and complex continuing care hospital were recruited to participate in a 50-60 min Hatha Yoga class (modified for wheelchair users/seated position) once a week for eight weeks, with assigned homework practice. Questionnaires on pain (pain, pain interference, and pain catastrophizing), psychological variables (depression, anxiety, and experiences with injustice), mindfulness, self-compassion, and spiritual well-being were collected at three intervals: pre-, mid-, and post-intervention. Results. Repeated measures ANOVAs revealed a significant main effect of time indicating improvements over the course of the yoga program on the (1) anxiety subscale of the Hospital Anxiety and Depression Scale, $F(2,18)=4.74, p<.05$, and $\eta_{p}{ }^{2}=.35$, (2) Self-Compassion Scale-Short Form, $F(2,18)=3.71, p<.05$, and $\eta_{p}{ }^{2}=.29$, and (3) Magnification subscale of the Pain Catastrophizing Scale, $F(2,18)$ $=3.66, p<.05$, and $\eta_{p}{ }^{2}=.29$. Discussion. The results suggest that an 8-week Hatha Yoga program improves pain-related factors and psychological experiences in individuals admitted to a rehabilitation and complex continuing care hospital.
\end{abstract}

\section{Introduction}

Yoga is an ancient mind-body practice that is embedded in Vedic traditions dating back to $3000 \mathrm{BC}$ [1] and which is being applied in developed countries as a broad remedy to attenuate health-related symptoms in clinical populations $[2,3]$ across institutional, community, commercial, and private settings. Yoga is traditionally understood as cultivating concentrative awareness and a unified experience of the self through physical postures (āsana), breathing exercises (prānāyāma), inner awareness (pratyāhāra), concentration (dhāranāā), and meditation (dhyāna), with consequent improved health through a separation process from afflictive cognitive, emotional, behavioural, and autonomic patterns and a shift towards adaptive coping skills $[4,5]$.
Yoga is garnering attention for its ability to simultaneously address multiple body systems (e.g., circulatory, neuroendocrine, musculoskeletal, respiratory, viscerosomatic, and immunological) through a dynamic and bidirectional process consisting of both top-down and bottom-up constituents and to yield benefits in well-being and symptom reduction $[3,5]$. Burgeoning interest in yoga as a therapeutic intervention for a variety of health conditions has resulted in an expansion of research over the past decade, with the volume of publications increasing by threefold with up to 312 randomized controlled studies noted in 2013 [6, 7]. There are a plethora of lineages and schools of yoga that are evaluated in yoga research trials, but the style of yoga (e.g., aștannga, iyengar, and hatha) does not impact the odds of producing positive outcomes for different conditions [8]. Across many of 
these studies, yoga is extolled for its many benefits. However, the literature is plagued by studies of poor methodological quality and there has been a call for improving the caliber of research in this area [9].

There is evidence that yoga is effective in the treatment of a variety of acute and chronic conditions [9] either as a standalone treatment or as an adjuvant therapy, including low back pain $[10,11]$, arthritis [12], rheumatic disease and fibromyalgia $[13,14]$, diabetes $[15,16]$, cancer and related fatigue [1721], stroke and related disability [22, 23], sleep disorders [24], renal disease [25, 26], hypertension [27, 28], asthma $[29,30]$, chronic obstructive pulmonary disease (COPD) [31], psychiatric conditions [32], obesity [33], and neurological conditions [34, 35]. Although there is an abundance of research evaluating the impact of yoga on disease-specific symptoms or quality of life for many chronic conditions, to date there has not been one trial evaluating the effects of a yoga intervention on individuals who are receiving care or rehabilitation for complex chronic disease and disability (CCDD).

CCDD is a term that identifies individuals who have been diagnosed with multimorbidities that affect psychological, social, physical, and vocational functioning and require ongoing health care resource utilization [36-38]. Individuals with complex health conditions have been identified as unique in terms of their specific health care needs and healthrelated experiences [36]. Although the disease combinations reported in multimorbidity are diverse, the most common diagnoses are diabetes, stroke, hypertension, cancer, arthritis, asthma, fractures, the presence of an artificial knee or hip, fatigue, multiple sclerosis, demyelinating diseases of the central nervous system, gonarthrosis, ataxia, COPD, dependence on renal dialysis, malignant neoplasm of breast/prostate, depressive episodes, and pure hypercholesterolemia [39, 40]. Consistent across studies of this population is the severity of the impact of having multiple conditions [41]. Patients with CCDD have an average of five health conditions (comorbidities) [40] and frequently reported pain, weakness, illnessrelated symptoms, functional challenges (mobility, activities of daily living, equipment devices, etc.), symptoms of anxiety and depression, and disruptions in independence, recreational activities, occupation, social roles, and self-identity.

Multimorbidity has been associated with low socioeconomic status, female gender, and older age in both longitudinal and cross-sectional studies, with prevalence and incidence rates in older age reported at 55\% and $12-33 \%$, respectively, and prevalence rates in young-middle age at $11.3-15.4 \%$ [42-45]. Multimorbidity is a complex and heterogeneous disease state, with many of the most prevalent conditions being of global concern, and is increasingly becoming the norm rather than the exception, resulting in high health care resource use $[45,46]$. In Canada, $42 \%$ of total direct medical care expenses are allotted to the treatment of chronic diseases [47], with up to $\$ 52,661$ per patient spent on average for the last year of life, in part due to inpatient and long-term care costs [48]. Despite the clear priority of the medical community to address the needs of individuals with chronic disease, the orientation of the health care system as an acute-care focused model means that care for individuals with chronic disease is often ineffective, leaving those with many chronic conditions underserviced [49].

A structural shift towards care that is not disease/injury focused but emphasizes addressing many needs at once has been recommended $[50,51]$. Understanding the relationships between physical, psychological, and social factors of health in multimorbidity has been identified as necessary for creating effective treatment $[38,52]$. A remodeling of chronic disease services has been proposed to create interventions that harmoniously integrate patient-centered and systemic factors and that also target risk factors, such as depression or functional ability, with the end goal of improving patient selfefficacy, functional health status, health-related behaviours, and psychological well-being $[49,53]$. Despite an increase in research over the past two decades on multimorbidity, there is still limited research on effective interventions to adequately service this population $[53,54]$, which highlights a need for programs that are designed to address the needs of individuals who are managing multiple intersecting health impacts of a chronic nature.

Given the evidence supporting the use of yoga for many of the common primary and secondary diagnoses of patients with CCDD (e.g., musculoskeletal conditions, multiple sclerosis, hypertension, arthritis, renal disease, depression, diabetes, COPD, cholesterol levels, and breast and prostate cancer), it is possible that yoga may be able to address many of the multiple health needs these individuals report as being important [40]. Other frequently reported symptoms (e.g., pain, fatigue, emotional upset, nausea, and difficulty breathing) and facets of living that are disrupted (e.g., mobility, activities of living, and social well-being) have also been shown to improve with yoga practice $[2,19,21,55,56]$. Moreover, yoga provides a lasting behavioural skill set that increases confidence and self-efficacy and shows maintenance of functional and coping gains in chronic pain patients at follow-up [57]. It can be used in the treatment of chronic conditions for both low- and high-income populations, is associated with treatment adherence in sedentary adults, and holds promise as a cost-effective treatment for chronic conditions [58-61]. Complementary and alternative therapies such as yoga have been recommended for integration into clinical health psychology settings in order to more broadly address well-being, spirituality, multiple health problems, dissatisfaction with orthodox medicine, and disease prevention [62].

Although there is evidence that yoga provides mental and physical health benefits for many of the disease states and psychosocial impacts that are prevalent in individuals with multimorbidity, there have been no studies evaluating its use for this population. Medical rehabilitation and complex continuing care support tend to focus on addressing physical ailments and neglect integrating mental health support. Yoga is an example of a strategy that addresses both; thus it may impart benefits in multiple areas of health, rendering it particularly useful for this population. Hospital and tertiary care settings typically implement evidence-based practice, so there is a need for information regarding the benefits and safety of yoga when used in the treatment of individuals with CCDD or multimorbidity. 
TABLE 1: Demographics of the sample $(N=10)$.

\begin{tabular}{lc}
\hline Demographic & $N(\%) / M(\mathrm{sd})$ \\
\hline Age $($ years $)$ & $63.1(16.6)$ \\
Height $(\mathrm{cm})$ & $163.6(15.4)$ \\
Weight $(\mathrm{kg})$ & $70.7(17.1)$ \\
Race/ethnicity & \\
$\quad$ African Canadian & $2(20 \%)$ \\
European (Italian/Croatian) & $2(20 \%)$ \\
Caucasian & $6(60 \%)$ \\
Socioeconomic class & \\
High & $1(10 \%)$ \\
Middle-high & $1(10 \%)$ \\
Middle & $1(10 \%)$ \\
Middle-low & $2(20 \%)$ \\
Low & $5(50 \%)$ \\
Level of education $(n=9)$ & \\
Grade school & $2(22.2 \%)$ \\
High school & $2(22.2 \%)$ \\
University/college & $5(55.6 \%)$ \\
Postgraduate school & $0(0 \%)$ \\
\hline
\end{tabular}

This study evaluated the impact of a specialized yoga program on pain, psychological, functional, and spiritual constructs in individuals receiving complex continuing care or medical rehabilitation. Given the complex presentation of impacts for this population, multiple measures were used to fully explore the possible effects of yoga across various aspects of experience. The study used a pilot cohort study design to test the following hypotheses: (1) scores on measures of pain, pain catastrophizing, stress, anxiety, depression, and experiences of injustice will decrease from pre- to postintervention and (2) scores on mindfulness, self-compassion, and spiritual well-being will increase from pre- to postintervention.

\section{Materials and Methods}

2.1. Participants. In order to be included in the study, participants had to be inpatients at Sinai Health System (Bridgepoint Hospital (BH) Site), be able to understand and speak English, and be cognitively able to understand instructions. Exclusion criteria included a regular yoga practice in the six months prior to the commencement of the study, an expected discharge date before the completion of the yoga program, or moderate cognitive impairment as indicated by a cognitive screen done by BH care team. Participants either were wheelchair users or were comfortable doing yoga from a seated position.

Demographic information and clinical characteristics of the sample are summarized in Table 1. Participants had all been admitted to $\mathrm{BH}$ in 2014 and were receiving either complex continuing care (CCC; $n=9$ ) or medical rehabilitation (MR; $n=1$ ). The one patient that was admitted for MR was informally transferred to CCC partway through the hospital stay for more intensive care. Examination of hospital records across a range of assessment dates indicated that participants had different levels of independence for tasks of daily living and mobility, such as transferring from a bed to a wheelchair. Information recorded within the hospital system is different for the complex continuing care and medical rehabilitation streams.

Both males $(n=4)$ and females $(n=6)$ participated in the yoga program. Height and weight were taken from hospital records for participants receiving CCC and if multiple weight assessments were provided, the weight assessment time closest to the start date of the yoga program was used. Weight and height were taken from self-report data for the participant receiving MR; secondary conditions were not reported for this patient. Participants had been diagnosed with at least one medical condition (see Table 2) and on average $7.6 \pm$ 2.8 conditions. Although most conditions were accompanied by a formal disease diagnosis, some documented conditions were not necessarily accompanied by diagnoses (e.g., weight issues, allergies, pain, and instability). Participant use of various pain treatments (pharmacological, natural health products, physical treatments, psychological treatments, and medical interventions) are displayed in Table 3. The study researchers worked with hospital staff to obtain medical clearance notes for all participants, indicating that it was safe for participants to participate in an eight-week yoga program. Participants did not receive financial compensation for participating in the study.

2.2. Procedure. The research protocol was reviewed and approved by the Human Participants Review Committee at York University and by the Joint Bridgepoint Health, West Park Healthcare Centre, Toronto Central Community Care Access Centre (CCAC), and Toronto Grace Health Centre Research Ethics Board.

2.3. Research Design. This prospective, pilot study consisted of two parts: a Codesign Phase and a Research Intervention Phase. The Codesign Phase involved consultation with $\mathrm{BH}$ staff (Therapeutic Recreation staff, research scientists, the Chair of Complex Chronic Disease Research, the Director of Professional Practice, and a liaison to the research ethics board) to discuss the best approach to the yoga program development, delivery, and evaluation so that it would contribute to meeting the complex needs of the patients. As depicted in Figure 1, the Research Intervention Phase consisted of several components: an information session, yoga classes, follow-up meetings, and administration of selfreport questionnaires. Questionnaires concerning pain and related variables, psychological factors, and mindfulness were administered at three time (T) points: pre- (T1), mid- (T2), and postintervention (T3). There were no subsequent data collection points in the time following the yoga intervention. The information session was held seven days before the yoga program began. The yoga program ran for eight weeks (one class/week) and the follow-up meetings took place after the final class and in the following few days. The information session and yoga classes were held in one of two auditoriums at the hospital. 
TABLE 2: Primary and secondary conditions by participant $(N=10)$.

\begin{tabular}{lll}
\hline Participant & Primary diagnoses & Secondary diagnoses \\
\hline 2 & Multiple sclerosis & Instability (report of having fallen). \\
\hline 3 & $\begin{array}{l}\text { End stage renal } \\
\text { disease }\end{array}$ & $\begin{array}{l}\text { Diabetes, hypertension, ischemic disease (unspecified), gastrointestinal issues, renal failure, } \\
\text { moderate pain (less than daily), general instability (report of having fallen). }\end{array}$ \\
\hline $\begin{array}{l}\text { Klippel-Feil } \\
\text { syndrome }\end{array}$ & Asthma, emphysema, moderate pain (daily), general instability (report of having fallen). \\
\hline 5 & Superficial injury & $\begin{array}{l}\text { Hypotension, cerebrodisease, arthritis, Parkinson's disease, asthma, moderate pain (both daily } \\
\text { and less than daily), general instability (report of having fallen). }\end{array}$ \\
\hline 6 & $\begin{array}{l}\text { Cervical spondylosis } \\
\text { pain (daily), general and acute instability (report of having fallen), skin issues (pressure ulcers, } \\
\text { rash). }\end{array}$ \\
\hline $\begin{array}{l}\text { Intracranial } \\
\text { hemorrhage (NOS, } \\
\text { nontraumatic) }\end{array}$ & $\begin{array}{l}\text { Hypertension, cardiovascular disease, aphasia, cerebrodisease, hemiplegia, allergies, pneumonia, } \\
\text { urinary tract infection, weight issue, edema, moderate pain (daily), general and acute instability. }\end{array}$ \\
\hline $\begin{array}{l}\text { Hyperkalemia } \\
\text { Neuromuscular } \\
\text { bladder dysfunction } \\
\text { (NOS) }\end{array}$ & $\begin{array}{l}\text { Diabetes, arthritis, pneumonia, moderate pain (daily), report of having falling. } \\
\text { Syncope and collapse } \\
\text { skin issues (pressure ulcers, rash, desensitized skin). }\end{array}$ \\
\hline $\begin{array}{l}\text { Neuromyelitis } \\
\text { optica/Devic's disease }\end{array}$ & $\begin{array}{l}\text { Hypertension, osteoporosis, depression, emphysema, gastrointestinal issues, moderate pain (less } \\
\text { than daily), report of having fallen, anxiety. }\end{array}$ \\
\hline $\begin{array}{l}\text { Hemiplegia, sclerosis, depression, gastrointestinal, urinary tract infection, moderate pain (daily), } \\
\text { general instability, skin issues (rash). }\end{array}$
\end{tabular}

TABLE 3: Pain medications and pain treatments previously or currently used $\left(N=7^{*}\right)$.

\begin{tabular}{lcc}
\hline Pain medications and treatments & $N(\%)$ & $\begin{array}{c}\text { Participant } \\
\text { number }\end{array}$ \\
\hline $\begin{array}{l}\text { Pharmacological medications (e.g., } \\
\text { opioid-based medications, } \\
\text { acetaminophen, and antidepressants) }\end{array}$ & $7(100 \%)$ & $1,3,4,5,7,8,10$ \\
$\begin{array}{l}\text { Natural health products (e.g., } \\
\text { supplements and vitamins) }\end{array}$ & $5(71.43 \%)$ & $1,3,4,5,8$ \\
$\begin{array}{l}\text { Physical treatments (e.g., massage, } \\
\text { acupuncture, physiotherapy, and }\end{array}$ & $5(71.43 \%)$ & $1,3,4,5,8$ \\
$\begin{array}{l}\text { exercise) } \\
\begin{array}{l}\text { Psychological treatments (e.g., } \\
\text { meditation, psychotherapy, } \\
\text { distraction, and relaxation) }\end{array}\end{array}$ & $3(42.86 \%)$ & $3,4,8$ \\
\hline
\end{tabular}

Note. ${ }^{*}$ Three participants did not record the use of pain medications or treatments.

2.4. Information Session and Data Collection. Interested individuals were informed about the yoga study by hospital staff (Therapeutic Recreation team members and support staff) and were screened for eligibility. Eligible participants attended the information session (T1) where they were given information about the investigators, the content of the yoga program, expectations for attendance and commitment, possible initial increases in pain due to exertion, and the homework component. Interested individuals had the opportunity to ask questions or voice concerns and those who decided to participate completed the consent process. After written informed consent was obtained, participants

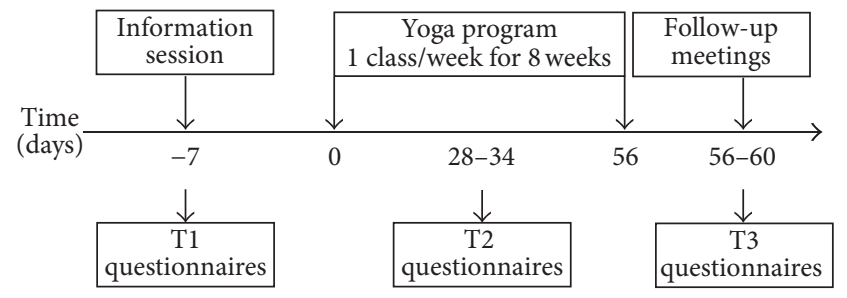

FIGURE 1: Time sequence of the study intervention. The information session was held seven days before the yoga program began. The yoga program was held once weekly for 8 weeks. Questionnaires measuring pain, pain-related variables, psychological factors, and mindfulness were evaluated at three time points: T1, T2, and T3.

were provided with a canvas tote folder, which included an MP3 player with the homework audio files (see yoga program description), a copy of the consent form for their records, and a handwritten instruction guide to using the MP3 player with accompanying illustrations. Participants filled out a form with questions regarding demographic information, health history and current health status, and the questionnaire package. At T2, participants had the option of remaining after the yoga class to fill out questionnaires or taking the questionnaires back to their hospital room to fill out prior to the following class. At T3, participants filled out the questionnaire package after the final class.

2.5. The Yoga Program. The specialized yoga program consisted of an integrated approach to Hatha Yoga: postures (āsana), breath awareness exercises (prānāyāma), concentrative, meditative, and relaxation practices (dhāraṇā, dhyāna), 
TABLE 4: Yoga philosophy concepts by class.

\begin{tabular}{|c|c|c|}
\hline Class number & Concept & Explanation \\
\hline 1 & $\begin{array}{l}\text { Witness consciousness and } \\
\text { ahimsā (nonviolence); Sūtra } 2.35 \text {. }\end{array}$ & $\begin{array}{l}\text { Practicing "being with" challenging experiences without pushing them away } \\
\text { or clinging to personal narratives. Practicing in a way that is safe and } \\
\text { supportive. }\end{array}$ \\
\hline 2 & Satya (truthfulness); Sūtra 2.36. & $\begin{array}{l}\text { Honestly examining one's experience to better understand one's "starting } \\
\text { point" and using yoga practice as a springboard for positive change. }\end{array}$ \\
\hline 3 & $\begin{array}{l}\text { Breath awareness to balance the } \\
\text { nervous system and calm the } \\
\text { mind; Sütra } 1.34 \text {. }\end{array}$ & $\begin{array}{l}\text { Pain management through relaxation, training the attention to see tension } \\
\text { patterns in the body, and using imagery and visualization. }\end{array}$ \\
\hline 4 & $\begin{array}{l}\text { Sthira sukham āsanam; Sūtra } \\
2.46 .\end{array}$ & Finding a balance between steadiness/stability/effort with ease/joy/relaxation. \\
\hline 5 & $\begin{array}{l}\text { Ekā gra (one pointed } \\
\text { concentration); Sūtra } 1.32 .\end{array}$ & $\begin{array}{l}\text { Training attention and concentration by returning to a point of focus } \\
\text { repeatedly. }\end{array}$ \\
\hline 6 & $\begin{array}{l}\text { Contemplation on the heart; } \\
\text { Sūtra 1.36. }\end{array}$ & The heart as a resource, refuge, and source of inner luminosity. \\
\hline 7 & $\begin{array}{l}\text { Contemplation of kośas } \\
\text { (sheaths/layers). }\end{array}$ & $\begin{array}{l}\text { Five sheaths of the self: physical (annamaya), breath (prānāmaya), mind } \\
\text { (manomaya), wisdom (vijñānamaya), and joy (ānandamaya). Practicing } \\
\text { experiencing parts of the self without identifying with them. }\end{array}$ \\
\hline 8 & Śavasana and the kośas. & $\begin{array}{l}\text { Consolidation of all concepts. Cultivation of awareness of the layers of the self } \\
\text { and a deeper part that can rest back and witness. }\end{array}$ \\
\hline
\end{tabular}

and yoga philosophy (jñāna) [63-65]. One of the most ancient scriptures of Hatha Yoga outlines yoga as a purificatory practice that balances the activities and processes of the physical body, the mind, and the overall energy level, in order to cultivate health, self-awareness, and inner development [65]. Hatha Yoga was selected as an appropriate form of yoga for individuals with chronic conditions and mobility restrictions as it is gentle and can be easily modified. The yoga philosophy component (see Table 4) was based on relevant contemplative and reflective practices from Patañjali Yoga Sūtras that focused on self-study, personal development, observances, yamas (ethical discipline), and attitudes of acceptance, among others [4, 64, 66]. Concepts found in classical scripture, such as the kośas theory of self, are being integrated in protocols for yoga interventions for chronic illness with a mind-body component [67]. The classes were one-third āsana, one-third relaxation training, and one-third yoga philosophy. The class format, structure, and content were designed in accordance with the yoga literature. A BH Recreation Therapy Assistant was present at each session. All participants practiced from a seated position, using either a wheelchair or a table chair to allow for uniform practice of the āsanas across participants.

Participants were provided with two recordings and were instructed to practice using the MP3 player twice a week. The first recording was a guided body scan awareness practice ( $\sim 30$ minutes) and the second recording was an āsana practice ( $\sim 15$ minutes). The participants were not given the second recording until they were familiar with the yoga àsanas and the teacher decided that they were safe to practice them on their own.

\subsection{Measures}

2.6.1. Brief Pain Inventory-Short Form (BPI-SF) [68]. The $\mathrm{BPI}-\mathrm{SF}$ is a 9-item self-report questionnaire that measures various aspects of pain and pain interference with daily activities. The Brief Pain Questionnaire [69] and the Brief Pain Inventory $[70,71]$ were originally developed to evaluate cancer-related pain and have since been validated for other types of pain $[72,73]$. In the BPI-SF, individuals are queried on pain history, are asked to visually depict pain locations on a human body diagram, and are asked to indicate best, worst, average, and current pain levels according to 11-point Likert scales, ranging from 0 (no pain) to 10 (pain as bad as you can imagine). Participants are also queried about pain medications and treatments and the perceived effectiveness of those medications. Finally, individuals respond to items regarding how pain interferes with seven domains of functioning: general activity, mood, walking ability, normal work, relations with other people, sleep, and enjoyment of life, according to 11-point scales ranging from 0 (does not interfere) to 10 (completely interferes).

The BPI has strong internal consistency (Cronbach's $\alpha=$ .85 and .88 for the intensity and interference scales, resp.), adequate construct validity (scores on the interference scale correlate with other pain disability measures) and is sensitive to treatment [70]. The BPI-interference items have been used in studies evaluating pain in individuals with SCI $[74,75]$ and have been recommended for use in this population, though item 9c, which refers to "Walking Ability," should be changed to "Ability to Get Around" [76]. It has excellent internal consistency $(\alpha>.90)$ and is positively associated with pain intensity $(r>$.60) [77]. 
2.6.2. Pain Catastrophizing Scale (PCS) [78]. The PCS is a 13-item self-report questionnaire that measures catastrophic thinking in relation to experienced or anticipated pain. Participants are asked to read each item and indicate the extent to which they experience certain thoughts and feelings when experiencing pain by selecting a number from 0 (not at all) to 4 (all the time). Scores range from 0 to 52, with higher scores reflecting higher levels of pain catastrophizing. The PCS yields a total score and three subscale scores assessing rumination (focus on pain sensations), magnification (exaggerating the threat value of pain sensations), and helplessness (perceiving oneself as unable to cope with pain symptoms). The PCS has high internal consistency (coefficient $\alpha$ : total $\mathrm{PCS}=.87$, rumination $=.87$, magnification $=.66$, and helplessness $=.78)[78]$.

2.6.3. Perceived Stress Scale (PSS) [79]. The PSS is a 10-item self-report questionnaire that measures symptoms of stress over the past month, in relation to life events and relationships. Participants indicate how much they are experiencing their life as unpredictable and uncontrollable and how much they have felt overloaded. Each item is rated on a 5-point scale, ranging from 0 (never) to 4 (very often), with a highest possible score of 40 , such that higher scores are indicative of higher levels of stress. It correlates well with other measures of stress, such as life events, and depression and anxiety scales and has satisfactory internal reliability $(\alpha=.78-.82)$ and testretest reliability $(r=.55-.85)[79,80]$.

2.6.4. Hospital Anxiety and Depression Scale (HADS) [81]. The HADS is a 14 -item self-report questionnaire that measures symptoms of anxiety ( 7 items) and depression ( 7 items). For each item, participants are asked to select one from among four possible choices (scored from 0 to 3 ) that best describes how they have been feeling over the past week. The HADS yields an anxiety (HADS-A) and a depression (HADS-D) subscale score, each with a maximum total score of 21, where higher scores indicate higher levels of anxiety and depression. Scores of 8-10 are considered cut-off points that are clinically meaningful for symptoms of anxiety and depression [81]. Internal consistency is high for both the HADS-A $(\alpha=.83)$ and HADS-D $(\alpha=.82)$ subscales [82]. Concurrent validity of the HADS is very good, as measured by correlation coefficients of between .62 and .73 for the HADS-D with various well-validated depression scales and correlation coefficients of between .49 and .81 for the HADSA with various well-validated anxiety measures [82].

2.6.5. Injustice Experiences Questionnaire (IEQ) [83]. The IEQ is a 12-item questionnaire that evaluates feelings and thoughts of perceived injustice and severity of loss in relation to injury or pain. This scale is designed to evaluate cognitive appraisals that contribute to pain-related occupational disability. Individuals answer each item using a 5-point scale, ranging from 0 (never) to 4 (all the time). This scale has a total score and two subscales, blame/unfairness and severity/irreparability of loss. The total scale has good internal consistency $(\alpha=.92)$ and all items correlated above .05 with the total score [83]. This scale has been correlated with pain severity, pain catastrophizing, fear of movement, perceived disability, and depression $(r=.54-.75, p<.01)$, indicating good construct validity. Cross-sectional regression analysis has shown good discriminant validity in that IEQ contributes to the variance of the predication of pain severity $(\beta=.44$, $p<.05)$ [83]. Test-retest variability of the IEQ is good and scores across time are stable $(r=.90, p<.01)$; authors note that the test-retest scores were more stable than scores on measures of pain and related constructs (e.g., PCS, Pain Disability Index, and McGill Pain Questionnaire) [83].

2.6.6. Five-Facet Mindfulness Questionnaire-Short Form (FFMQ-SF) [84]. The FFMQ-SF is a 24 -item version of the original 39-item FFMQ and has been validated in individuals with depression, anxiety, and fibromyalgia [84]. It is a self-report questionnaire that measures levels of mindfulness according to five facets, which have acceptable model fit with the five-factor structure of the FFMQ. Those facets are observing, describing, acting with awareness, nonjudging of inner experience, and nonreactivity to inner experience. Participants respond to each item by selecting the number that is "most generally true" of his/her experience, on a scale of 1 (never or rarely true) to 5 (very often or always true). Total scores range from 0 to 120 and higher scores indicate greater levels of mindfulness. The FFMQ is based on a factor analytic study of five independently developed mindfulness questionnaires, with good internal consistency and construct validity $[85,86]$. Total facet scores of the FFMQ-SF are highly correlated with the original version, $r=.89, .89, .92$, .96 , and .95 , for observing, describing, acting with awareness, nonjudging, and nonreactivity, respectively [84]. The correlation alphas are all above the defined criterion of 7 and all intercorrelations between facets and with other constructs are very virtually the same as the FFMQ. All the facets of the FFMQ-SF are sensitive to change and had moderate-large effect sizes [84].

2.6.7. Self-Compassion Scale-Short Form (SCS-SF) [87]. The SCS-SF is a self-report 12 -item version of the original 26 -item questionnaire [88] that measures levels of self-compassion. Self-compassion, as measured by this scale, is defined as the ability to hold one's feelings of suffering with a sense of warmth, security, or concern [87]. This short form has been demonstrated to have a unidimensional construct of selfcompassion and also a multidimensional construct consisting of 6 subscales including self-kindness, self-judgement, common humanity, isolation, mindfulness, and overidentified; however, it is not recommended to use subscales for the short form version. The questionnaire queries respondents to indicate "how I typically act towards myself in difficult times," according to a scale of 1 (almost never) to 5 (almost always). This scale has been shown to have adequate internal consistency (Cronbach's $\alpha \geq .86$ for three different samples) and good correlation with the full version $(r \geq .97$ for three samples). The total score for the short form is calculated by dividing the total score by 12 (for each item) to produce a mean score (personal communication with Kristen Neff, April 19, 2016). 


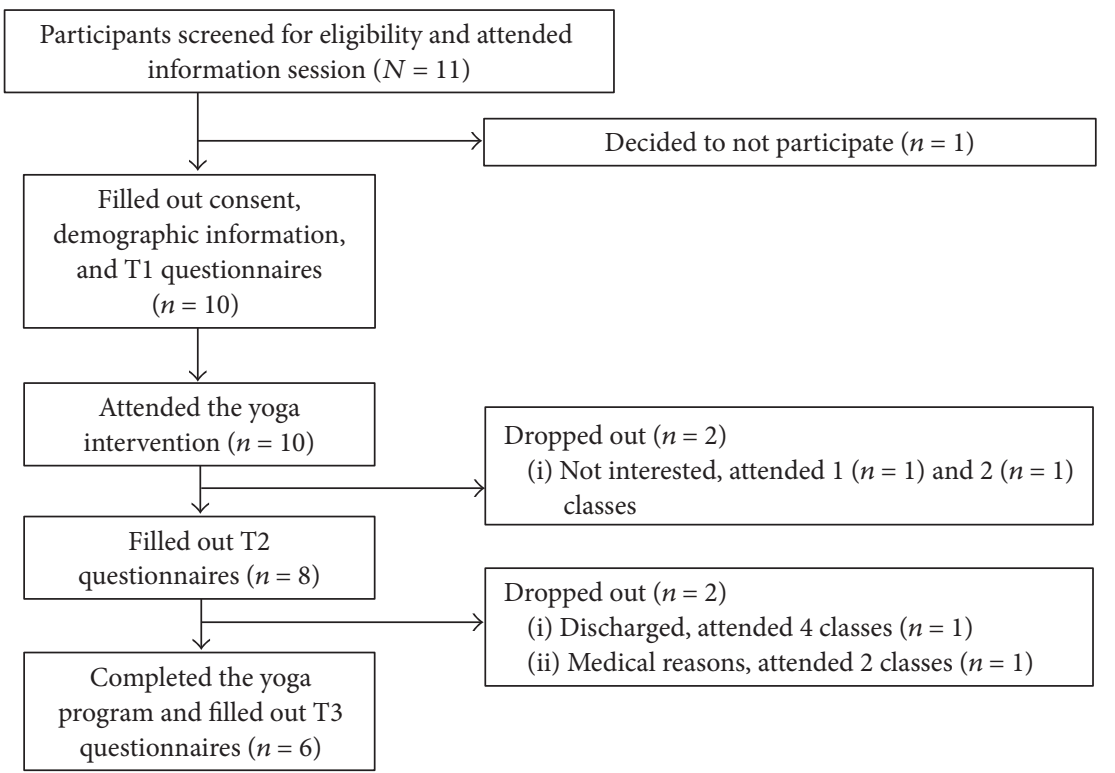

FIgURE 2: Participant flow through the study.

2.6.8. Functional Assessment of Chronic Illness TherapySpiritual Well-Being (FACIT-SpWB) [89]. The FACIT-SpWB is a 12-item self-report questionnaire that evaluates experiences of spirituality in individuals with chronic illnesses. The original scale has a total score and two subscales: meaning/peace and faith, although confirmatory factor analysis has validated the three-factor model in which meaning and peace are unique subscales [90]. Questions query themes of harmony and peacefulness and a sense of strength and comfort in one's beliefs. Participants answer each item using 5-point Likert scale, from 0 (not at all) to 4 (very much). This scale has good internal consistency for the overall index and for the two subscales $(\alpha=.81-.88)$. This scale also shows good validity; both the total scale and each subscales were positively correlated with measures of quality of life in cancer patients (Functional Assessment of Cancer Therapy-General) and negatively with measure of mood (Profile of Mood States) [89].

2.7. Data Analysis. Statistical Analysis was performed using SPSS Version 23 and SAS Version 94. Exploratory analysis was conducted to evaluate missing data and assumptions of normality. Raw data were evaluated for skew and kurtosis. All self-report measures were assessed for normality using the Shapiro-Wilk test. The self-report data were analyzed using repeated measures ANOVAs (T1, T2, and T3) and Bonferroni post hoc analysis in the presence of a significant main effect of time. Sphericity was evaluated using Mauchly's Test of Sphericity and, in the case of violations, HuynhFeldt adjustments were used. Simple mediation analysis was conducted using a bootstrapping approach (2,000 resamples), as recommended for small sample sizes which may have violations of normality [91], to evaluate the mediating effect of total SCS scores at T2 on the relationship between HADS-A scores at $\mathrm{T} 1$ and $\mathrm{T} 3$.

\section{Results}

3.1. Preparation of Data. Data were analyzed by a protocol compliance (PC; $n=6$ ) and intention-to-treat approach (ITT; $N=10$ ). Although one of the participants had missed yoga classes 3 and 4 due to medical reasons, data were collected for this participant at T2 as they had not formally withdrawn from the study by that time. Therefore, for ITT analysis, data were carried forward from T1 for two participants and from T2 for two participants. One participant did not fill out the HADS questionnaire at T1, so T2 scores for this participant were used as a baseline score.

Data were explored for assumptions of normality. Values of kurtosis and skewness for all total scale scores at each time point were converted to $z$-scores for both PC and ITT data. At T1, all were within normal limits $(<|1.96|$ at $p<.05)$ except BPI-3 (significant skew). For PC data, all were within normal limits $(<|1.96|$ at $p<.05)$ except BPI-3 at T3 (significant kurtosis and skew) and BPI-5 at T3 (significant skew). For ITT data, all were within normal limits $(<|1.96|$ at $p<.05)$ except BPI-3 at T3 (and significant skew) and SCS-SF at T3 (significant skew). Similarly, the Shapiro-Wilk test revealed that all total scale scores were normal at $p<.05$, with the exception of violations of normality for BPI-3, $W(10)=.81$, $p<.05$, and BPI-6 at T1, $W(10)=.84, p<.05$, BPI-3-PC at $\mathrm{T} 2, W(8)=.80, p<.05$, BPI-3-PC at T3, $W(5)=.55, p<.05$, BPI-3-ITT at T3, $W(10)=.81, p<.05, \mathrm{BPI}-4-\mathrm{PC}$ at T3, $W(5)$ $=.75, p<.05$, BPI-4-ITT at T3, $W(10)=.84, p<.05$, BPI5 -ITT at T3, $W(10)=.81, p<.05$, and SCS-SF-total-ITT at T3, $W(10)=.74, p<.05$. Table 5 shows the means and sds for each measure across the three time points, as well as significant $p$ values and effect sizes.

3.2. Demographic and Clinical Variables. Figure 2 shows the flow of participants through the study, which ran from October 28 to December 16, 2014. Eleven participants were 
TABLE 5: Mean (sd) values for pain, psychological, and mindfulness variables across time, using Intent-to-treat sample $(N=10)$.

\begin{tabular}{|c|c|c|c|c|}
\hline Measure & Preintervention (T1) & Midintervention (T2) & Postintervention (T3) & Significance ( $p$ value) \\
\hline BPI-SF-3 & $6.90(3.14)$ & $6.80(2.66)$ & $6.90(2.81)$ & ns \\
\hline BPI-SF-4 & $4.50(3.57)$ & $3.60(3.20)$ & $2.70(2.54)$ & ns \\
\hline BPI-SF-5 & $5.20(3.49)$ & $4.50(2.95)$ & $5.00(2.91)$ & ns \\
\hline BPI-SF-6 & $6.80(3.33)$ & $5.30(3.71)$ & $4.60(3.47)$ & ns \\
\hline BPI-9-SF-total & $29.10(21.27)$ & $23.70(16.40)$ & $25.50(17.82)$ & ns \\
\hline PCS-total & $25.30(15.62)$ & $21.30(14.77)$ & $19.30(12.19)$ & .099 \\
\hline PCS-helplessness & $11.40(8.58)$ & $9.20(8.20)$ & $8.70(6.45)$ & ns \\
\hline PCS-magnification & $4.50(3.72)$ & $2.70(3.74)$ & $2.40(2.59)$ & $.047^{\mathrm{b}}$ \\
\hline PCS-rumination & $9.40(5.06)$ & $9.60(4.70)$ & $8.20(4.98)$ & ns \\
\hline PSS & $20.20(7.83)$ & $19.00(8.27)$ & $15.70(8.17)$ & ns \\
\hline IEQ-total & $23.50(7.11)$ & $20.10(9.55)$ & $21.10(11.49)$ & ns \\
\hline IEQ-blame/unfairness & $10.20(4.13)$ & $8.10(4.46)$ & $8.60(6.10)$ & ns \\
\hline IEQ-severity/irreparability & $13.30(4.35)$ & $12.00(5.91)$ & $12.50(6.00)$ & ns \\
\hline HADS-A & $9.00(5.64)$ & $7.70(5.19)$ & $6.50(4.38)$ & .022 \\
\hline HADS-D & $6.70(4.99)$ & $5.70(3.83)$ & $5.80(4.05)$ & ns \\
\hline FFMQ-SF-total & $84.40(7.66)$ & $86.60(10.05)$ & $87.40(12.40)$ & ns \\
\hline FFMQ-SF-observing & $15.70(2.16)$ & $16.80(2.20)$ & $16.80(2.15)$ & ns \\
\hline FFMQ-SF-describing & $19.50(2.64)$ & $19.10(3.87)$ & $19.10(4.09)$ & ns \\
\hline FFMQ-SF-acting with awareness & $18.10(1.79)$ & $19.60(3.06)$ & $18.60(4.20)$ & ns \\
\hline FFMQ-SF-nonjudging & $16.90(4.18)$ & $16.70(4.37)$ & $17.10(5.02)$ & ns \\
\hline FFMQ-SF-nonreactivity & $14.20(2.20)$ & $14.40(3.10)$ & $15.80(4.87)$ & ns \\
\hline SCS-SF & $3.28(0.77)$ & $3.57(0.63)$ & $3.44(0.58)$ & $.047^{\mathrm{a}}$ \\
\hline FACIT-SpWB-total & $33.80(8.13)$ & $35.00(9.01)$ & $36.00(7.45)$ & ns \\
\hline FACIT-SpWB-faith & $11.80(4.57)$ & $11.00(5.29)$ & $12.00(5.29)$ & ns \\
\hline FACIT-SpWB-meaning & $12.70(2.45)$ & $13.50(2.84)$ & $12.70(2.16)$ & ns \\
\hline FACIT-SpWB-peace & $9.30(3.62)$ & $10.50(2.55)$ & $11.30(2.50)$ & ns \\
\hline
\end{tabular}

Note. Greenhouse-Geisser adjusted $F$-tests for significant main effects of time were conducted for SCS-SF.

Note. BPI-SF: Brief Pain Inventory-Short Form, PCS: Pain Catastrophizing Scale, PSS: Perceived Stress Scale-10 Items, IEQ: Injustice Experiences Questionnaire, HADS-A: Hospital Anxiety and Depression Scale-Anxiety, HADS-D: Hospital Anxiety and Depression Scale-Depression, FFMQ-SF: Five-Facet Mindfulness Questionnaire-Short Form, SCS-SF: Self-Compassion Scale-Short Form, FACIT-SpWB: Functional Assessment of Chronic Illness Therapy-Spiritual Wellbeing. Note. ${ }^{\mathrm{a}} p<0.1$ for $\mathrm{T} 1$ versus $\mathrm{T} 2{ }^{\mathrm{b}} p<0.1$ for T1 versus T3.

recruited by hospital staff and attended the information session, 10 of whom provided consent, filled out T1 questionnaires, and participated in at least one class of the yoga program. One participant decided not to participate after learning more about the questionnaire component of the research study. Data for eight and six participants were obtained at $\mathrm{T} 2$ and $\mathrm{T} 3$, respectively.

3.3. Yoga Program Attendance. Of the 10 participants who started the yoga program, six $(60 \%)$ completed it. Three participants attended 1-2 classes and withdrew for personal or medical reasons, while one participant attended 4 classes, after which she withdrew as she was discharged early from the hospital. The mean \pm sd number of yoga classes attended for all participants who entered the program $(N=10)$ was $3.72 \pm 2.54$ (out of 8 classes) and the mean \pm sd number of yoga classes attended for all participants who completed the program $(n=6)$ was $6.83 \pm 0.75$ (out of 8 ). The mean \pm sd number of participants who did some homework each week (listened to a recording $1-4$ times) was $4.0 \pm 1.83$.

\subsection{Treatment Results}

3.4.1. Pain and Related Variables, Psychological Factors, and Mindfulness. Repeated measures ANOVAs did not reveal significant changes in any variable across time for the PC analyses. All analyses are reported according to the ITT principle as outlined above. Repeated measures ANOVAs revealed a significant main effect of time for HADS-A, $F(2,18)=4.74, p<.05$, and $\eta_{p}{ }^{2}=.35$, for SCS-SF-total (Greenhouse-Geisser adjusted $F$-test), $F(2,18)=3.71, p<$ .05 , and $\eta_{p}{ }^{2}=.29$, and for PCS-magnification, $F(2,18)=3.66$, $p<.05$, and $\eta_{p}{ }^{2}=.29$. Bonferroni comparisons revealed a trend for improvement from T1 to T2 for SCS-SF-total, $p<$ .07 , and for PCS-magnification from $\mathrm{T} 1$ to $\mathrm{T} 3, p=.08$. A repeated measures ANOVA also revealed a trend of improvement for main effects of time for PCS-total, $F(2,18)$ $=2.63, p=.099$, and $\eta_{p}{ }^{2}=.23$. Individual score trajectories for scales with significant changes or trends for improvement are shown in Figure 3. 

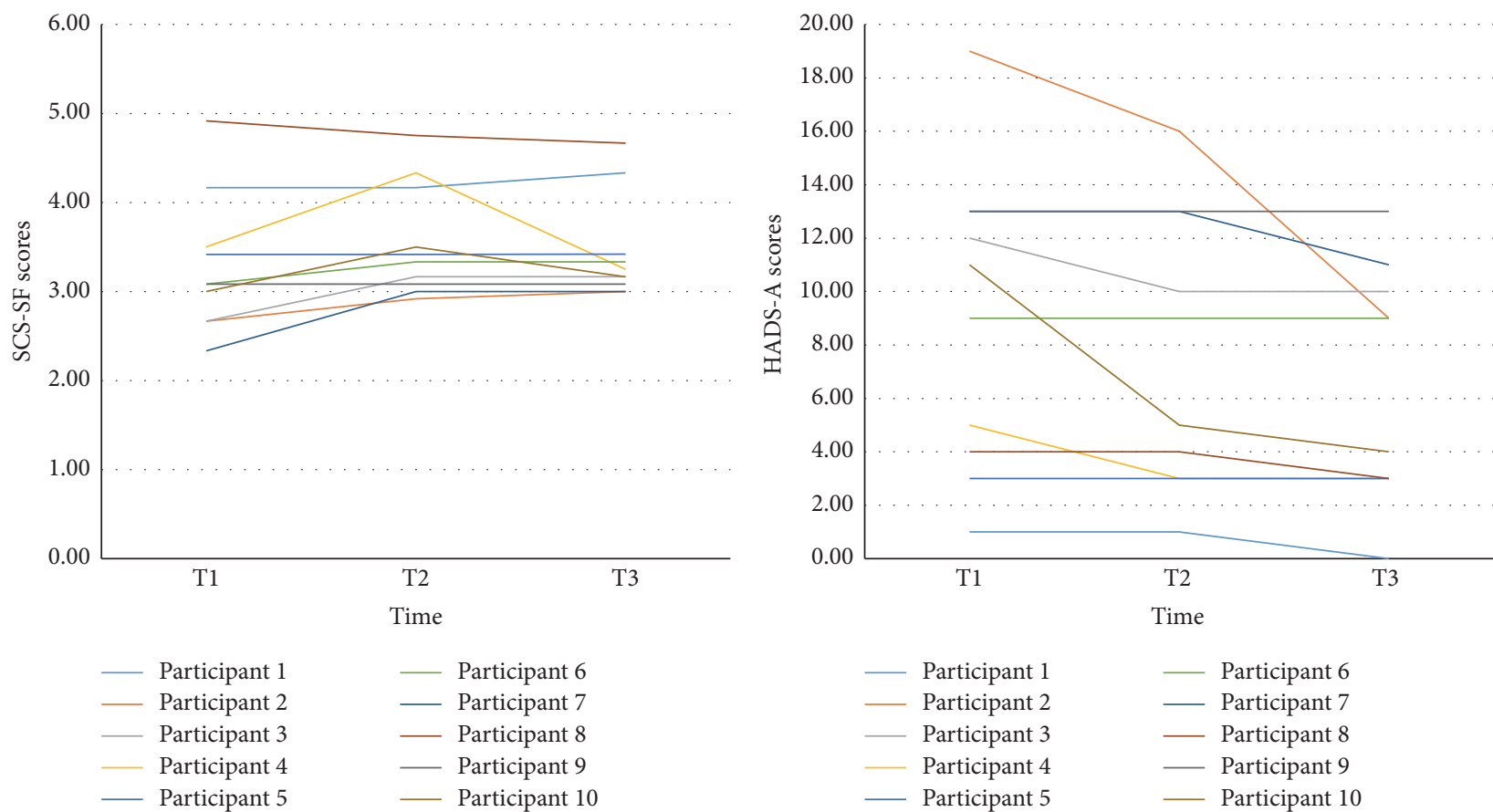

(b)
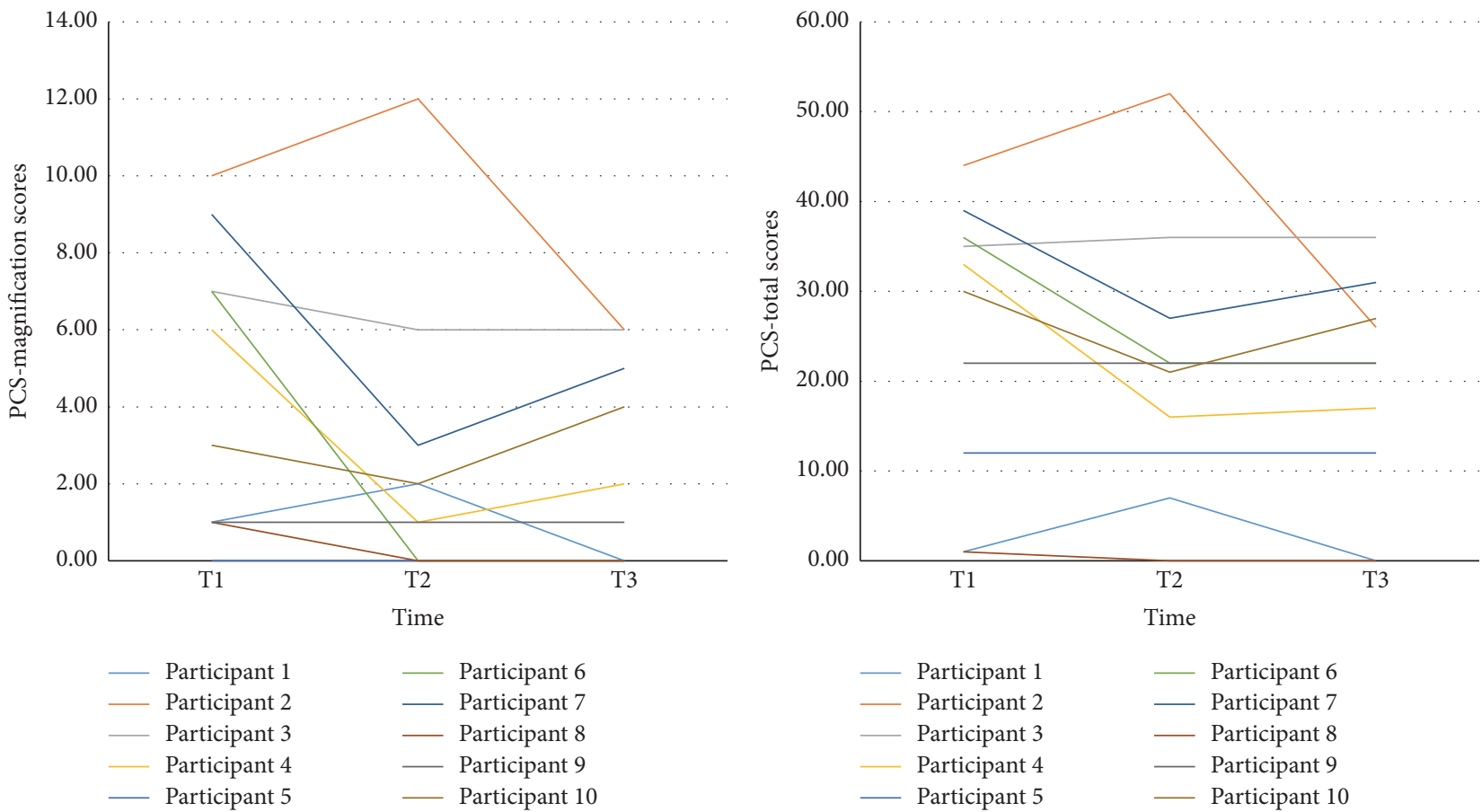

(c)

(d)

FIgURE 3: (a) Individual participant Self-Compassion Scale-SF (SCS-SF) scores by time. (b) Individual participant Hospital Anxiety and Depression Scale-Anxiety (HADS-A) scores by time. (c) Individual participant Pain Catastrophizing Scale (PCS)-magnification subscale scores by time. (d) Individual participant Pain Catastrophizing Scale (PCS)-total scores by time.

In terms of clinically meaningful cut-off points, 6 participants had scores above 8 on the HADS-A subscale at T1 and 4 participants had scores at or above 8 on the HADS-D subscale at T1. Out of the six true completers at the end of the study, there were 2 participants with scores above 8 on the HADS-A subscale and 1 participant with a score above 8 for the HADS-D subscale. Using the ITT scores for all participants, there were 5 participants with scores above 8 on the HADS-A subscale and 2 participants with a score above 8 for the HADS-D subscale. Visual inspection of the ITT 
data revealed that each participant's score for HADS-A and HADS-D remained the same or decreased with the exception of 1 participant, whose score increased 2 points from $\mathrm{T} 1$ to $\mathrm{T} 3$ on HADS-D.

3.4.2. Mediation Analysis. Nonparametric bootstrapping analysis showed that the total effect of HADS-A scores at baseline on HADS-A scores at the end of the intervention was significantly reduced when SCS-SF scores at midintervention (the mediator) were added to the model (mean $=0.35$, SEM $=0.33 \mathrm{CI}_{.95}=0.05,1.41$ ). As such, the true indirect effect is estimated to lie between .05 and 1.41 with $95 \%$ confidence; as zero is not within the CI interval, it can be concluded that the indirect effect is significantly different than zero, $p<.05$, and that mid-treatment SCS-SF scores mediated the relationship between baseline and end-of-treatment HADS-A scores.

\section{Discussion}

This pilot study is the first reported trial to evaluate the effects of a yoga intervention on pain and related variables, psychological constructs, spirituality, and mindfulness in a sample of inpatients receiving complex continuing care/rehabilitation for multimorbidities. The results demonstrate post-intervention improvements in anxiety symptoms, the magnification aspect of pain catastrophizing, and selfcompassion. As well, self-compassion was found to mediate improvements in anxiety from pre- to postintervention. These results suggest that a Hatha Yoga program specifically tailored to the needs of a hospitalized population experiencing multimorbidities may provide some psychological benefits.

The finding that anxiety scores were significantly lower after the eight-week program is consistent with RCTs that demonstrated improvements in anxiety and health outcomes in individuals with chronic diseases (diabetes or chronic low back pain) who participated in a yoga intervention when compared to walking or exercise/counselling control groups $[92,93]$. A recent cross-sectional assessment of a large sample of individuals with a range of chronic illnesses found that self-reported duration of practice (practice session length and number of months practicing) predicted anxiety and the authors concluded that increased doses of yoga practice may help individuals respond to illness with lower levels of anxiety [94]. As well, systematic reviews document improvements in anxiety for several health populations that have participated in a yoga intervention, such as cancer, stroke, and irritable bowel syndrome $[19,31,95]$. In addition, low-income or noninsured individuals who participated in an integrated program involving mindfulness, self-compassion, and yoga, according to a single-group, repeated measures design, were found to have lower levels of anxiety and depression after intervention [96]. It is apparent that yoga provides psychological symptom improvement in both health populations and those who are impacted by low health care resources. This combination of experiences (health concerns, anxiety symptoms, financial strain, and a lack of resources) parallels the presentation of individuals with CCDD and indicates that yoga may reduce anxiety in the context of multiple healthrelated impacts.

Although pain catastrophizing has been less well studied in yoga trials, two studies (one pilot, one RCT) found that levels of pain catastrophizing were reduced from pre- to postyoga interventions in samples of women with fibromyalgia $[97,98]$. The present results are consistent with these studies in that we found the magnification aspect of pain catastrophizing (e.g., "I wonder whether something serious might happen") decreased from pre- to post-intervention. Pain catastrophizing is a strong predictor of pain severity, pain-related interference, disability, depression, and altered social support networks [99] and is associated with physical function deterioration in individuals with joint pain and comorbidity [100], highlighting it as a useful target for interventions that intend to increase functional ability in individuals with multimorbidity or CCDD. Other painrelated psychosocial factors, such as pain disability and pain acceptance, have been shown to improve with yoga practice [101]. Taken together, these findings provide some evidence that yoga may help to reduce the threat value attributed to pain stimuli or alter pain-related experiences in individuals with medical conditions in which pain is a predominant feature. As well, the potentially debilitating impact of painrelated disability or chronic health stress on financial and social independence for individuals with CCDD may amplify magnification cognitions, pointing to the utility of targeting this construct in yoga interventions.

The benefits of yoga extend beyond decreasing negative cognitive-affective experiences and can also serve to generate or augment a nurturing, positive, and discriminative approach to engaging with inner experiences. Selfcompassion is a Buddhist concept that is increasingly being considered as an important mental health construct in Western Psychology and entails three main components: selfkindness, common humanity, and mindfulness [102]. The present findings that self-compassion increased significantly from pre- to post-intervention parallel the results from a yoga research trial in individuals living with an implantable cardioverter defibrillator [103]. The results of that study showed that participants who were randomized to a once weekly, eight-week yoga intervention reported increased selfcompassion at the end of the trial compared to a usual care group [103]. For individuals with severe health impacts who typically use avoidance or distancing as coping strategies, a yoga practice may enable them to contact suffering and pain without judgmental or comparative thoughts [102]. Yoga philosophy didactics, which explain that inadequacies, failings, and suffering are considered part of the human condition (shared humanity), may normalize challenging experiences and enable individuals with CCDD to extend forgiveness towards their own short-comings and pain, rather than orienting from the stigma and marginalization that can accompany disability.

4.1. Mechanisms of Action. The finding that self-compassion mediated decreases in anxiety provides some support for selfcompassion as a protective agent in distressing psychological experience and in helping to understand how yoga may be 
exerting its mechanism of action. This construct has been identified in the yoga literature as one of seven possible mediators of yoga and stress; other mediators include psychological (positive self-affect and mindfulness) and biological (activity in the posterior hypothalamus and inflammatory and endocrine responses: C-reactive protein, Interleukin-6, and cortisol) pathways for therapeutic effects [104]. This is the first study to date that demonstrated the mediating role of self-compassion on psychological changes in a population experiencing medical concerns who participate in a yoga program. There is one previous trial that has demonstrated self-compassion and mindfulness as mediators of quality of life and stress in healthy young adults who participated in a four-month residential yoga intensive [105]. By contrast, selfcompassion and mindful attention were not found to mediate changes in emotional stability in high school students who participated in a 16-week yoga program, when compared to students who participated in physical education as usual [106].

This construct may be more amenable to facilitating secondary mental health benefits in individuals experiencing illness-related duress and may impact how individuals cope with chronic and debilitating illnesses. It has been shown to change emotional responses, such as shame, and increase positive coping behaviours in individuals living with HIV and it predicts positive attitudes in the elderly, potentially serving as a buffer against the inevitable challenges associated with age decline $[107,108]$. In addition, it is positively associated with both intentions to engage with and practice of health-promoting behaviours (e.g., eating habits, stress management, exercise, and sleep) with indirect effects through adaptive emotions (e.g., health self-efficacy, and positive affect), in community samples of Canadian adults [109, 110]. As the risk of multimorbidity increases with age, augmenting adaptive emotional responses to illness and health-promoting behaviours may assist in the prevention of further health decline and the promotion of wellbeing.

Although mindfulness was not a mediator of positive psychological change in the present study, previous yoga trials have reported that mid-intervention levels of mindfulness mediated changes in pain catastrophizing from preto postyoga intervention in women with fibromyalgia [97]. It may be that these constructs work by exerting different mechanisms during a yoga practice or that one may be more potent as a mediator for different populations or types of mindfulness or yoga interventions. Self-compassion has been demonstrated to be a more robust predictor of symptom severity (e.g., anxious and depressive symptoms) and quality of life than mindfulness in a large community sample of individuals seeking self-help for anxious distress and predicts emotional well-being more consistently than mindfulness in a sample of youth participating in a 5-day meditation retreat $[111,112]$. Further examination between psychological well-being, mindfulness, self-compassion, and disability for individuals with CCDD in the context of a yoga intervention is warranted.
4.2. Attending to the Signals of the Body: New Pathways. The role of interoception, which is a complex and multimodal bodily system involving a sense of body parts in space (proprioception) and the act of attending, appraising, and responding to afferent body signals [113], has been considered as one of yoga's underlying mechanisms of action through the process of interoceptive exposure and reconditioning [97]. It is proposed that mind-body interventions, such as yoga, may interrupt habitual ways of perceiving and interpreting body sensations within the context of higher-order cognitive processes, such as goals and intentions, by connecting an individual with the present moment and with their agency for personal change [113]. In addition, it has been proposed that higher level brain networks that are activated by yoga practice may serve to inhibit negative appraisals, rumination, and emotional reactivity while lower level neural networks may downregulate physiological responses to stress, such as inflammatory markers and vasopulminary restriction, through the activation of the parasympathetic nervous system [5]. This is relevant in interpreting the results that pain catastrophizing decreased from pre- to post-interventions, as this construct involves exaggerated or negative cognitiveemotional appraisal of painful stimuli as threatening, is accompanied by perceived helplessness (lack of power), and is associated with aberrant central nervous system processes, such as cytokine or hypothalamic-pituitary-adrenal responses to pain, and activation of neural regions involved in processing affective components of pain [99]. It is clear that pain catastrophizing is a construct involving both emotional and biological processes and it may be that yoga helps individuals to reinterpret physical body signals for what they are, rather than as dangerous threats, through two elements of practice, practicing witness consciousness and then actively creating positive change in the body, which is then reinforced with practice through operant conditioning.

Self-compassion mirrors these two elements of traditional yoga practice, in that it involves a truthful recognition of one's inner state and selecting responses or behaviours that will alleviate suffering. It may be that, through yoga, individuals discover safety in opening to distressing experiences, circumventing, or offering a protective buffer against engrained ruminative or punitive "self-talk," and thereby create new ways of relating to self and prioritizing actions that are consistent with well-being and values. Higher levels of self-compassion have been associated with lower levels of catastrophizing, avoidance, and rumination in chronic pain patients who were presented with vignettes involving a violation of social contract and have been found to predict affect, pain disability, and pain catastrophizing in obese patients with chronic pain $[114,115]$. The relationships between self-compassion, anxiety, and disability have been explored in individuals with Generalized Anxiety Disorder; these individuals display lower levels of self-compassion and mindfulness than healthy stressed controls and mindfulness was a better predictor of disability than actual anxiety symptoms, drawing potential protective effects of mindfulness on disability in individuals with chronic worry and physiological symptoms [116]. The relationship between self-compassion and anxiety should be further elucidated and it may be useful 
to examine the relationships between the subscales of the SCS to better understand which components of self-compassion are most helpful in mediating changes in anxiety in clinical populations.

4.3. Limitations. There are limitations to the present study. The primary weakness is the absence of a control group, which is a shortcoming that is widespread in the yoga research literature, and makes it impossible to attribute the improvements observed to the yoga practice itself. As well, the small sample size limits power and introduces the possibility of type II error. Logistical limitations included participant difficulty in using the MP3 players and, as a result, reducing homework engagement and completion, which may have reduced overall efficacy of the eight-week yoga intervention. The difficulties that these patients experienced when using the technology are consistent with a previous report indicating that this population has challenges in paying attention and in using assistive technology [117]. Although the research team carefully selected devices with few buttons and minimal steps required to turn on and navigate the devices and also provided large print diagram instructions to accompany the devices, the population still experienced difficulty, which illustrates that they may be better serviced by yoga interventions that do not involve assistive technology for homework components.

4.4. Future Research. The researchers hope that these findings will be considered in the design and implementation of future research projects for individuals who are experiencing CCDD and associated pain, limited mobility, loss of functional ability, severe health impacts, and psychological sequelae. Future research trials should use a randomized, controlled trial study design with appropriate control conditions (e.g., wait-list, exercise, walking, or education) and a longitudinal design with follow-up intervals to determine lasting effects of a yoga practice [118]. Targeting self-compassion in the content and philosophy portions of the yoga interventions may enable researchers to further explore its mediating role of this construct on other psychological or physical experiences prevalent in this population. Trials that seek to further illuminate processes that underlie therapeutic gains may wish to use measures of self-regulation, self-compassion, stress, and positive affect alongside neuroendocrine-inflammatory markers of physiological status [104]. Evaluation of how these variables interact with pain-related constructs associated with the fear-avoidance model of chronic pain (e.g., chronic pain acceptance, pain-related disability, fear of pain, pain anxiety, and pain self-efficacy) may be warranted to better understand the converging impacts that result in distress and disability and with the end purpose to improve health and well-being.

\section{Conclusions}

The results of the present pilot project suggest that an eightweek specialized yoga program may help to reduce anxiety and the magnification component of pain catastrophizing and to increase self-compassion in patients with multimorbidity. This study provides preliminary evidence for yoga as an auxiliary care service that may be amenable to institutions that are in the process of evolving from single-disease treatment frameworks and that are seeking to assimilate programs and services that can address multiple, intersecting health concerns for various ages. The use of a randomized, controlled trial with a larger sample size and a more intensive yoga intervention design (e.g., two or more classes a week for 10-12 weeks) is recommended to further explore the relationships among pain, psychological experience, and mindfulness or spiritual constructs in individuals who are severely impacted by disease and disability.

\section{Competing Interests}

The authors declare that they have no competing interests.

\section{Acknowledgments}

Joel Katz is supported by a Canadian Institutes of Health Research (CIHR) Canada Research Chair in Health Psychology. Kathryn Curtis is supported by a CIHR Health Professional Student Research Award. This research project was conducted in partial fulfillment of the requirements for Kathryn Curtis' doctoral dissertation.

\section{References}

[1] G. Feuerstein, The Yoga Tradition; Its History, Literature, Philosophy and Practice Prescott, Hohm Press, Chino Valley, Ariz, USA, 2008.

[2] T. Field, "Yoga clinical research review," Complementary Therapies in Clinical Practice, vol. 17, no. 1, pp. 1-8, 2011.

[3] A. A. Wren, M. A. Wright, J. W. Carson, and F. J. Keefe, "Yoga for persistent pain: new findings and directions for an ancient practice," Pain, vol. 152, no. 3, pp. 477-480, 2011.

[4] G. Bechsgaard, The Gift of Consciousness; Patanjali's Yoga Sutras (Book One: Samadhi Pada), Cambridge Scholars Publishing, Newcastle, UK, 2013.

[5] T. Gard, J. J. Noggle, C. L. Park, D. R. Vago, and A. Wilson, "Potential self-regulatory mechanisms of yoga for psychological health," Frontiers in Human Neuroscience, vol. 8, article 770, 2014.

[6] P. E. Jeter, J. Slutsky, N. Singh, and S. B. S. Khalsa, "Yoga as a therapeutic intervention: a bibliometric analysis of published research studies from 1967 to 2013," Journal of Alternative and Complementary Medicine, vol. 21, no. 10, pp. 586-592, 2015.

[7] H. Cramer, R. Lauche, and G. Dobos, "Characteristics of randomized controlled trials of yoga: a bibliometric analysis," BMC Complementary and Alternative Medicine, vol. 14, article 328, 2014.

[8] H. Cramer, R. Lauche, J. Langhorst, and G. Dobos, "Is one yoga style better than another? A systematic review of associations of yoga style and conclusions in randomized yoga trials," Complementary Therapies in Medicine, vol. 25, pp. 178-187, 2016.

[9] M. C. McCall, A. Ward, N. W. Roberts, and C. Heneghan, "Overview of systematic reviews: yoga as a therapeutic intervention for adults with acute and chronic health conditions," 
Evidence-based Complementary and Alternative Medicine, vol. 2013, Article ID 945895, 18 pages, 2013.

[10] C. Hill, "Is yoga an effective treatment in the management of patients with chronic low back pain compared with other care modalities-a systematic review," Journal of Complementary and Integrative Medicine, vol. 10, no. 1, pp. 211-219, 2013.

[11] S. Holtzman and R. T. Beggs, "Yoga for chronic low back pain: a meta-analysis of randomized controlled trials," Pain Research and Management, vol. 18, no. 5, pp. 267-272, 2013.

[12] M. Sharma, "Yoga as an alternative and complementary approach for arthritis: a systematic review," Journal of EvidenceBased Complementary and Alternative Medicine, vol. 19, no. 1, pp. 51-58, 2014.

[13] L. Ward, S. Stebbings, D. Cherkin, and G. D. Baxter, "Yoga for functional ability, pain and psychosocial outcomes in musculoskeletal conditions: a systematic review and meta-analysis," Musculoskeletal Care, vol. 11, no. 4, pp. 203-217, 2013.

[14] H. Cramer, R. Lauche, J. Langhorst, and G. Dobos, "Yoga for rheumatic diseases: a systematic review," Rheumatology, vol. 52, no. 11, pp. 2025-2030, 2013.

[15] K. E. Innes and T. K. Selfe, "Yoga for adults with type 2 diabetes: a systematic review of controlled trials," Journal of Diabetes Research, vol. 2016, Article ID 6979370, 23 pages, 2016.

[16] V. Kumar, A. Jagannathan, M. Philip, A. Thulasi, P. Angadi, and N. Raghuram, "Role of yoga for patients with type II diabetes mellitus: a systematic review and meta-analysis," Complementary Therapies in Medicine, vol. 25, pp. 104-112, 2016.

[17] J. Sadja and P. J. Mills, "Effects of yoga interventions on fatigue in cancer patients and survivors: a systematic review of randomized controlled trials," Explore, vol. 9, no. 4, pp. 232-243, 2013.

[18] M. Sharma, T. Haider, and A. P. Knowlden, "Yoga as an alternative and complementary treatment for cancer: a systematic review," Journal of Alternative and Complementary Medicine, vol. 19, no. 11, pp. 870-875, 2013.

[19] L. M. Buffart, J. G. Z. van Uffelen, I. I. Riphagen et al., "Physical and psychosocial benefits of yoga in cancer patients and survivors, a systematic review and meta-analysis of randomized controlled trials," BMC Cancer, vol. 12, article no. 559, 2012.

[20] A. N. R. Zahavich, J. A. Robinson, D. Paskevich, and S. N. CulosReed, "Examining a therapeutic yoga program for prostate cancer survivors," Integrative Cancer Therapies, vol. 12, no. 2, pp. 113-125, 2013.

[21] H. Harder, L. Parlour, and V. Jenkins, "Randomised controlled trials of yoga interventions for women with breast cancer: a systematic literature review," Supportive Care in Cancer, vol. 20, no. 12, pp. 3055-3064, 2012.

[22] W. Chan, M. A. Immink, and S. Hillier, "Yoga and exercise for symptoms of depression and anxiety in people with poststroke disability: a randomized, controlled pilot trial," Alternative Therapies in Health and Medicine, vol. 18, no. 3, pp. 34-43, 2012.

[23] A. Lazaridou, P. Philbrook, and A. A. Tzika, "Yoga and mindfulness as therapeutic interventions for stroke rehabilitation: a systematic review," Evidence-Based Complementary and Alternative Medicine, vol. 2013, Article ID 357108, 9 pages, 2013.

[24] K. M. Mustian, "Yoga as treatment for insomnia among cancer patients and survivors: a systematic review," European Medical Journal Oncology, vol. 1, pp. 106-115, 2013.

[25] M. Yurtkuran, A. Alp, M. Yurtkuran, and K. Dilek, "A modified yoga-based exercise program in hemodialysis patients: a randomized controlled study," Complementary Therapies in Medicine, vol. 15, no. 3, pp. 164-171, 2007.
[26] L. Gordon, D. McGrowder, Y. Pena, E. Cabrera, and M. Lawrence Wright, "Effect of yoga exercise therapy on oxidative stress indicators with end-stage renal disease on hemodialysis," International Journal of Yoga, vol. 6, no. 1, pp. 31-38, 2013.

[27] N. R. Okonta, "Does yoga therapy reduce blood pressure in patients with hypertension? An integrative review," Holistic Nursing Practice, vol. 26, no. 3, pp. 137-141, 2012.

[28] P. Posadzki, H. Cramer, A. Kuzdzal, M. S. Lee, and E. Ernst, "Yoga for hypertension: a systematic review of randomized clinical trials," Complementary Therapies in Medicine, vol. 22, no. 3, pp. 511-522, 2014.

[29] H. Cramer, P. Posadzki, G. Dobos, and J. Langhorst, "Yoga for asthma: a systematic review and meta-analysis," Annals of Allergy, Asthma and Immunology, vol. 112, no. 6, pp. 503.e5510.e5, 2014.

[30] J. Wise, "Yoga may improve asthma symptoms, Cochrane review finds," BMJ, vol. 353, article i2462, p. i2462, 2016.

[31] L. Desveaux, A. Lee, R. Goldstein, and D. Brooks, "Yoga in the management of chronic disease: a systematic review and metaanalysis," Medical Care, vol. 53, no. 7, pp. 653-661, 2015.

[32] M. Balasubramaniam, S. Telles, and P. M. Doraiswamy, "Yoga on our minds: a systematic review of yoga for neuropsychiatric disorders," Frontiers in Psychiatry, vol. 3, article 117, 2013.

[33] R. Lauche, J. Langhorst, M. S. Lee, G. Dobos, and H. Cramer, "A systematic review and meta-analysis on the effects of yoga on weight-related outcomes," Preventive Medicine, vol. 87, pp. 213232, 2016.

[34] Y. Colgrove, N. Sharma, K. Robbins, and K. Wagner, "A randomized controlled pilot study of the therapeutic effects of yoga in people with Parkinson/s disease," International Journal of Yoga, vol. 8, no. 1, pp. 74-79, 2015.

[35] H. Cramer, R. Lauche, H. Azizi, G. Dobos, and J. Langhorst, "Yoga for multiple sclerosis: a systematic review and metaanalysis," PLoS ONE, vol. 9, no. 11, Article ID el12414, 2014.

[36] K. Kuluski, C. M. Bensimon, C. Alvaro, R. F. Lyons, A. K. Schaink, and R. Tobias, "Life interrupted: the impact of complex chronic disease from the perspective of hospitalized patients," Illness Crisis and Loss, vol. 22, no. 2, pp. 127-144, 2014.

[37] C. Steele Gray, A. I. Khan, K. Kuluski et al., "Improving patient experience and primary care quality for patients with complex chronic disease using the electronic patient-reported outcomes tool: adopting qualitative methods into a user-centered design approach," JMIR Research Protocols, vol. 5, no. 1, article e28, 2016.

[38] A. Schaink, K. Kuluski, R. Lyons et al., "A scoping review and thematic classification of patient complexity: offering a unifying framework," Journal of Comorbidity, vol. 2, pp. 1-9, 2012.

[39] A. J. Pefoyo, S. E. Bronskill, A. Gruneir et al., "The increasing burden and complexity of multimorbidity," BMC Public Health, vol. 15, article 415, 2015.

[40] K. Kuluski, S. N. Hoang, A. K. Schaink et al., "The care delivery experience of hospitalized patients with complex chronic disease," Health Expectations, vol. 16, no. 4, pp. ell1-e123, 2013.

[41] C. Diederichs, K. Berger, and D. B. Bartels, “The measurement of multiple chronic diseases-a systematic review on existing multimorbidity indices," Journals of Gerontology Series A: Biological Sciences and Medical Sciences, vol. 66, no. 3, pp. 301-311, 2011.

[42] A. Marengoni, S. Angleman, R. Melis et al., "Aging with multimorbidity: a systematic review of the literature," Ageing Research Reviews, vol. 10, no. 4, pp. 430-439, 2011. 
[43] A. Marengoni, B. Winblad, A. Karp, and L. Fratiglioni, "Prevalence of chronic diseases and multimorbidity among the elderly population in Sweden," American Journal of Public Health, vol. 98, no. 7, pp. 1198-1200, 2008.

[44] R. Melis, A. Marengoni, S. Angleman, and L. Fratiglioni, "Incidence and predictors of multimorbidity in the elderly: a population-based longitudinal study," PLoS ONE, vol. 9, no. 7, Article ID e103120, 2014.

[45] C. Violán, Q. Foguet-Boreu, A. Roso-Llorach et al., "Burden of multimorbidity, socioeconomic status and use of health services across stages of life in urban areas: A Cross-Sectional Study," BMC Public Health, vol. 14, no. 1, article 530, 2014.

[46] K. Barnett, S. W. Mercer, M. Norbury, G. Watt, S. Wyke, and B. Guthrie, "Epidemiology of multimorbidity and implications for health care, research, and medical education: a cross-sectional study," The Lancet, vol. 380, no. 9836, pp. 37-43, 2012.

[47] M. Mirolla, The Cost of Chronic Disease in Canada, The Chronic Disease Prevention Alliance of Canada, Ottawa, Canada, 2004.

[48] P. Tanuseputro, W. P. Wodchis, R. Fowler et al., "The health care cost of dying: a population-based retrospective cohort study of the last year of life in Ontario, Canada," PLoS ONE, vol. 10, no. 3, Article ID e0121759, 2015.

[49] M. Fortin, M.-C. Chouinard, T. Bouhali, M.-F. Dubois, C. Gagnon, and M. Bélanger, "Evaluating the integration of chronic disease prevention and management services into primary health care," BMC Health Services Research, vol. 13, no. 1, article no. 132, 2013.

[50] M. K. Andrew and K. Rockwood, "Making our health and care systems fit for an ageing population: considerations for Canada," Canadian Geriatrics Journal, vol. 17, no. 4, pp. 133-135, 2014.

[51] A. Kothari, D. Gore, M. MacDonald, G. Bursey, D. Allan, and J. Scarr, "Chronic disease prevention policy in British Columbia and Ontario in light of public health renewal: a comparative policy analysis," BMC Public Health, vol. 13, no. 1, article 934, 2013.

[52] M. Fortin, C. Hudon, E. A. Bayliss, H. Soubhi, and L. Lapointe, "Caring for body and soul: the importance of recognizing and managing psychological distress in persons with multimorbidity," International Journal of Psychiatry in Medicine, vol. 37, no. 1, pp. 1-9, 2007.

[53] S. M. Smith, E. Wallace, T. O’Dowd, and M. Fortin, "Interventions for improving outcomes in patients with multimorbidity in primary care and community settings," The Cochrane Database of Systematic Reviews, no. 3, Article ID CD006560, 2016.

[54] G. Onder, K. Palmer, R. Navickas et al., "Time to face the challenge of multimorbidity. A European perspective from the joint action on chronic diseases and promoting healthy ageing across the life cycle (JA-CHRODIS)," European Journal of Internal Medicine, vol. 26, no. 3, pp. 157-159, 2015.

[55] A. Fulambarker, B. Farooki, F. Kheir, A. S. Copur, L. Srinivasan, and S. Schultz, "Effect of yoga in chronic obstructive pulmonary disease," American Journal of Therapeutics, vol. 19, no. 2, pp. 96100, 2012.

[56] G. A. Ghasemi, A. Golkar, and S. M. Marandi, "Effects of hata yoga on knee osteoarthritis," International Journal of Preventive Medicine, vol. 4, supplement 1, pp. S133-S138, 2013.

[57] J. W. Carson, K. M. Carson, K. D. Jones, S. D. Mist, and R. M. Bennett, "Follow-up of yoga of awareness for fibromyalgia: results at 3 months and replication in the wait-list group," Clinical Journal of Pain, vol. 28, no. 9, pp. 804-813, 2012.
[58] S. Bryan, G. P. Zipp, and R. Parasher, "The effects of yoga on psychosocial variables and exercise adherence: a randomized, controlled pilot study," Alternative Therapies in Health and Medicine, vol. 18, no. 5, pp. 50-59, 2012.

[59] A. Büssing, A. Michalsen, S. B. S. Khalsa, S. Telles, and K. J. Sherman, "Effects of yoga on mental and physical health: a short summary of reviews," Evidence-Based Complementary and Alternative Medicine, vol. 2012, Article ID 165410, 7 pages, 2012.

[60] L.-H. Chuang, M. O. Soares, H. Tilbrook et al., "A pragmatic multicentered randomized controlled trial of yoga for chronic low back pain: economic evaluation," Spine, vol. 37, no. 18, pp. 1593-1601, 2012.

[61] R. B. Saper, A. R. Boah, J. Keosaian, C. Cerrada, J. Weinberg, and K. J. Sherman, "Comparing once-versus twice-weekly yoga classes for chronic low back pain in predominantly low income minorities: a randomized dosing trial," Evidence-Based Complementary and Alternative Medicine, vol. 2013, Article ID 658030, 13 pages, 2013.

[62] C. Park, "Mind-body CAM interventions: current status and considerations for integration into clinical health psychology," Journal of Clinical Psychology, vol. 69, no. 1, pp. 45-63, 2013.

[63] B. K. S. Iyengar, Light on Yoga, HarperCollins Publishers, London, UK, 2010.

[64] B. K. S. Iyengar, Light on Pranayama: The Definitive Guide to the Art of Breathing, Harper Thorsons, London, UK, 2013.

[65] S. Muktibodhananda, Hatha Yoga Pradipika: Light on Hatha Yoga, Yoga Publications Trust, Bihar, India, 2005.

[66] B. K. S. Iyengar, Core of the Yoga Sutras, HarperThorsons, London, UK, 2012.

[67] V. Kavuri, N. Raghuram, A. Malamud, and S. R. Selvan, "Irritable bowel syndrome: yoga as remedial therapy," Evidence-Based Complementary and Alternative Medicine, vol. 2015, Article ID 398156, 10 pages, 2015.

[68] T. R. Mendoza, C. Chen, A. Brugger et al., "The utility and validity of the modified Brief Pain Inventory in a multiple-dose postoperative analgesic trial," Clinical Journal of Pain, vol. 20, no. 5, pp. 357-362, 2004.

[69] R. L. Daut, C. S. Cleeland, and R. C. Flanery, "Development of the Wisconsin Brief Pain Questionnaire to assess pain in cancer and other diseases," Pain, vol. 17, no. 2, pp. 197-210, 1983.

[70] C. S. Cleeland, "Pain assessment in cancer," in Effect of Cancer on Quality of Life, D. Osaba, Ed., CRC Press, Boca Raton, Fla, USA, 1991.

[71] C. S. Cleeland and K. M. Ryan, "Pain assessment: global use of the Brief Pain Inventory," Annals of the Academy of Medicine Singapore, vol. 23, no. 2, pp. 129-138, 1994.

[72] S. Keller, C. M. Bann, S. L. Dodd, J. Schein, T. R. Mendoza, and C. S. Cleeland, "Validity of the brief pain inventory for use in documenting the outcomes of patients with noncancer pain," Clinical Journal of Pain, vol. 20, no. 5, pp. 309-318, 2004.

[73] G. Tan, M. P. Jensen, J. I. Thornby, and B. F. Shanti, "Validation of the brief pain inventory for chronic nonmalignant pain," Journal of Pain, vol. 5, no. 2, pp. 133-137, 2004.

[74] M. P. Jensen, A. J. Hoffman, and D. D. Cardenas, "Chronic pain in individuals with spinal cord injury: a survey and longitudinal study," Spinal Cord, vol. 43, no. 12, pp. 704-712, 2005.

[75] M. W. Stroud, J. A. Turner, M. P. Jensen, and D. D. Cardenas, "Partner responses to pain behaviors are associated with depression and activity interference among persons with chronic pain and spinal cord injury," Journal of Pain, vol. 7, no. 2, pp. 91-99, 2006. 
[76] T. N. Bryce, C. N. Budh, D. D. Cardenas et al., "Pain after spinal cord injury: an evidence-based review for clinical practice and research-report of the National Institute on Disability and Rehabilitation Research Spinal Cord Injury Measures Meeting," Journal of Spinal Cord Medicine, vol. 30, no. 5, pp. 421-440, 2007.

[77] K. A. Raichle, T. L. Osborne, M. P. Jensen, and D. Cardenas, "The reliability and validity of pain interference measures in persons with spinal cord injury," Journal of Pain, vol. 7, no. 3, pp. 179-186, 2006.

[78] M. J. L. Sullivan, S. R. Bishop, and J. Pivik, "The pain catastrophizing scale: development and validation," Psychological Assessment, vol. 7, no. 4, pp. 524-532, 1995.

[79] S. Cohen, T. Kamarck, and R. Mermelstein, "A global measure of perceived stress," Journal of Health and Social Behavior, vol. 24, no. 4, pp. 385-396, 1983.

[80] E. Andreou, E. C. Alexopoulos, C. Lionis et al., "Perceived stress scale: reliability and validity study in Greece," International Journal of Environmental Research and Public Health, vol. 8, no. 8, pp. 3287-3298, 2011.

[81] A. S. Zigmond and R. P. Snaith, "The hospital anxiety and depression scale," Acta Psychiatrica Scandinavica, vol. 67, no. 6, pp. 361-370, 1983.

[82] I. Bjelland, A. A. Dahl, T. T. Haug, and D. Neckelmann, "The validity of the hospital anxiety and depression scale: an updated literature review," Journal of Psychosomatic Research, vol. 52, no. 2, pp. 69-77, 2002.

[83] M. J. L. Sullivan, H. Adams, S. Horan, D. Maher, D. Boland, and R. Gross, "The role of perceived injustice in the experience of chronic pain and disability: scale development and validation," Journal of Occupational Rehabilitation, vol. 18, no. 3, pp. 249261, 2008.

[84] E. Bohlmeijer, P. M. ten Klooster, M. Fledderus, M. Veehof, and R. Baer, "Psychometric properties of the five facet mindfulness questionnaire in depressed adults and development of a short form," Assessment, vol. 18, no. 3, pp. 308-320, 2011.

[85] R. A. Baer, G. T. Smith, J. Hopkins, J. Krietemeyer, and L. Toney, "Using self-report assessment methods to explore facets of mindfulness," Assessment, vol. 13, no. 1, pp. 27-45, 2006.

[86] R. A. Baer, G. T. Smith, E. Lykins et al., "Construct validity of the five facet mindfulness questionnaire in meditating and nonmeditating samples," Assessment, vol. 15, no. 3, pp. 329-342, 2008.

[87] F. Raes, E. Pommier, K. D. Neff, and D. Van Gucht, "Construction and factorial validation of a short form of the SelfCompassion Scale," Clinical Psychology \& Psychotherapy, vol. 18, no. 3, pp. 250-255, 2011.

[88] K. D. Neff, "The development and validation of a scale to measure self-compassion," Self and Identity, vol. 2, no. 3, pp. 223-250, 2003.

[89] A. H. Peterman, G. Fitchett, M. J. Brady, L. Hernandez, and D. Cella, "Measuring spiritual well-being in people with cancer: the functional assessment of chronic illness therapy-Spiritual Well-being Scale (FACIT-Sp)," Annals of Behavioral Medicine, vol. 24, no. 1, pp. 49-58, 2002.

[90] P. E. Murphy, A. L. Canada, G. Fitchett et al., "An examination of the 3-factor model and structural invariance across racial/ethnic groups for the FACIT-Sp: a report from the American Cancer Society's Study of Cancer Survivors-II (SCSII)," Psycho-Oncology, vol. 19, no. 3, pp. 264-272, 2010.

[91] K. J. Preacher and A. F. Hayes, "SPSS and SAS procedures for estimating indirect effects in simple mediation models,"
Behavior Research Methods, Instruments, and Computers, vol. 36, no. 4, pp. 717-731, 2004.

[92] K. A. McDermott, M. R. Rao, R. Nagarathna et al., "A yoga intervention for type 2 diabetes risk reduction: a pilot randomized controlled trial," BMC Complementary and Alternative Medicine, vol. 14, article 212, 2014.

[93] P. Tekur, R. Nagarathna, S. Chametcha, A. Hankey, and H. R. Nagendra, "A comprehensive yoga programs improves pain, anxiety and depression in chronic low back pain patients more than exercise: an RCT," Complementary Therapies in Medicine, vol. 20, no. 3, pp. 107-118, 2012.

[94] S. Telles, S. Pathak, A. Kumar, P. Mishra, and A. Balkrishna, "Influence of intensity and duration of yoga on anxiety and depression scores associated with chronic illness," Annals of Medical and Health Sciences Research, vol. 5, no. 4, pp. 260-265, 2015.

[95] D. Schumann, D. Anheyer, R. Lauche, G. Dobos, J. Langhorst, and H. Cramer, "Effect of Yoga in the therapy of irritable bowel syndrome: a systematic review," Clinical Gastroenterology and Hepatology, vol. 14, no. 12, pp. 1720-1731, 2016.

[96] N. Falsafi and L. Leopard, "Pilot study: use of mindfulness, self-compassion, and yoga practices with low-income and/or uninsured patients with depression and/or anxiety," Journal of Holistic Nursing, vol. 33, no. 4, pp. 289-297, 2015.

[97] K. Curtis, A. Osadchuk, and J. Katz, "An eight-week yoga intervention is associated with improvements in pain, psychological functioning and mindfulness, and changes in cortisol levels in women with fibromyalgia," Journal of Pain Research, vol. 4, pp. 189-201, 2011.

[98] J. W. Carson, K. M. Carson, K. D. Jones, R. M. Bennett, C. L. Wright, and S. D. Mist, "A pilot randomized controlled trial of the Yoga of Awareness program in the management of fibromyalgia," Pain, vol. 151, no. 2, pp. 530-539, 2010.

[99] P. J. Quartana, C. M. Campbell, and R. R. Edwards, "Pain catastrophizing: a critical review," Expert Review of Neurotherapeutics, vol. 9, no. 5, pp. 745-758, 2014.

[100] L. A. H. Hermsen, J. C. van der Wouden, S. S. Leone, M. Smalbrugge, H. E. van der Horst, and J. Dekker, “The longitudinal association of cognitive appraisals and coping strategies with physical functioning in older adults with joint pain and comorbidity: A Cohort Study," BMC Geriatrics, vol. 16, article 29, 2016.

[101] S. Evans, M. Moieni, K. Lung et al., "Impact of iyengar yoga on quality of life in young women with rheumatoid arthritis," Clinical Journal of Pain, vol. 29, no. 11, pp. 988-997, 2013.

[102] K. Neff, "Self-compassion: an alternative conceptualization of a healthy attitude toward oneself," Self and Identity, vol. 2, no. 2, pp. 85-101, 2003.

[103] S. C. F. Toise, S. F. Sears, M. H. Schoenfeld et al., "Psychosocial and cardiac outcomes of yoga for ICD patients: a randomized clinical control trial," Pacing and Clinical Electrophysiology, vol. 37, no. 1, pp. 48-62, 2014.

[104] K. E. Riley and C. L. Park, "How does yoga reduce stress? A systematic review of mechanisms of change and guide to future inquiry," Health Psychology Review, vol. 9, no. 3, pp. 379-396, 2015.

[105] T. Gard, N. Brach, B. K. Hölzel, J. J. Noggle, L. A. Conboy, and S. W. Lazar, "Effects of a yoga-based intervention for young adults on quality of life and perceived stress: the potential mediating roles of mindfulness and self-compassion," The Journal of Positive Psychology, vol. 7, no. 3, pp. 165-175, 2012. 
[106] L. A. Daly, S. C. Haden, M. Hagins, N. Papouchis, and P. M. Ramirez, "Yoga and emotion regulation in high school students: a randomized controlled trial," Evidence-Based Complementary and Alternative Medicine, vol. 2015, Article ID 794928, 8 pages, 2015.

[107] J. M. Brion, M. R. Leary, and A. S. Drabkin, "Self-compassion and reactions to serious illness: the case of HIV," Journal of Health Psychology, vol. 19, no. 2, pp. 218-229, 2014.

[108] A. B. Allen and M. R. Leary, "Self-compassionate responses to aging," Gerontologist, vol. 54, no. 2, pp. 190-200, 2014.

[109] F. M. Sirois, "A self-regulation resource model of self-compassion and health behavior intentions in emerging adults," Preventive Medicine Reports, vol. 2, pp. 218-222, 2015.

[110] F. M. Sirois, R. Kitner, and J. K. Hirsch, "Self-compassion, affect, and health-promoting behaviors," Health Psychology, vol. 34, no. 6, pp. 661-669, 2015.

[111] N. T. Van Dam, S. C. Sheppard, J. P. Forsyth, and M. Earleywine, "Self-compassion is a better predictor than mindfulness of symptom severity and quality of life in mixed anxiety and depression," Journal of Anxiety Disorders, vol. 25, no. 1, pp. 123130, 2011.

[112] B. M. Galla, "Within-person changes in mindfulness and selfcompassion predict enhanced emotional well-being in healthy, but stressed adolescents," Journal of Adolescence, vol. 49, pp. 204-217, 2016.

[113] N. Farb, J. Daubenmier, C. J. Price et al., "Interoception, contemplative practice, and health," Frontiers in Psychology, vol. 6, article 763, 2015.

[114] F. Purdie and S. Morley, "Self-compassion, pain, and breaking a social contract," Pain, vol. 156, no. 11, pp. 2354-2363, 2015.

[115] A. A. Wren, T. J. Somers, M. A. Wright et al., "Self-compassion in patients with persistent musculoskeletal pain: relationship of self-compassion to adjustment to persistent pain," Journal of Pain and Symptom Management, vol. 43, no. 4, pp. 759-770, 2012.

[116] E. A. Hoge, B. K. Hölzel, L. Marques et al., "Mindfulness and self-compassion in generalized anxiety disorder: examining predictors of disability," Evidence-based Complementary and Alternative Medicine, vol. 2013, Article ID 576258, 7 pages, 2013.

[117] R. Lyons, K. Kuluski, C. Alvaro, A. Shaink, B. Bernstein, and R. Tobias, Bridgepoint Collaboratory for Research and Innovation: The Face of Complex Chronic Disease: Understanding the Patient Population at Bridgepoint Health, Toronto, 2012.

[118] C. L. Park, E. Groessl, M. Maiya et al., "Comparison groups in yoga research: a systematic review and critical evaluation of the literature," Complementary Therapies in Medicine, vol. 22, no. 5, pp. 920-929, 2014. 


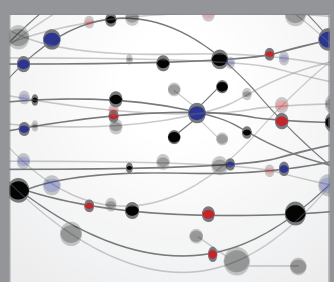

The Scientific World Journal
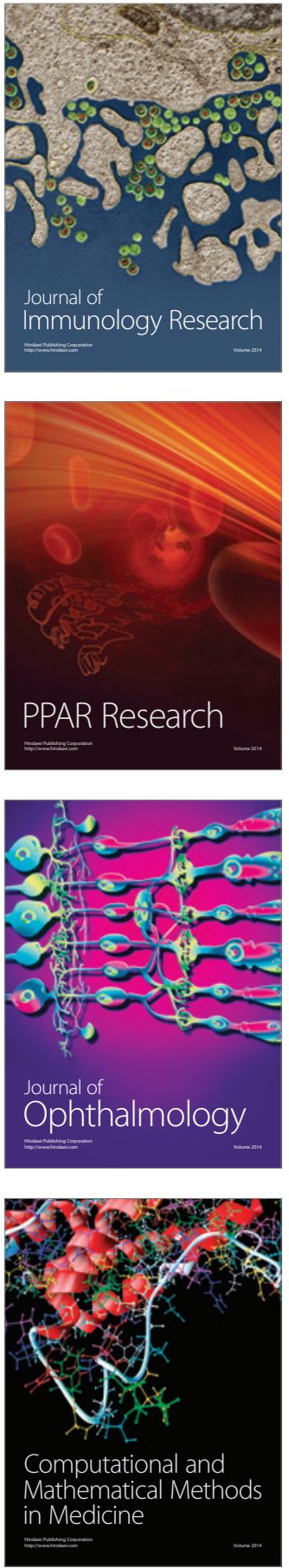

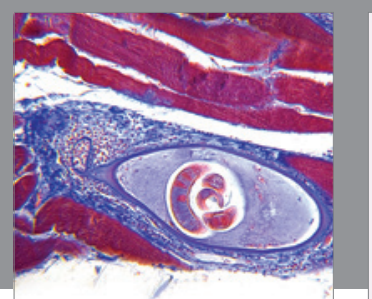

Gastroenterology Research and Practice

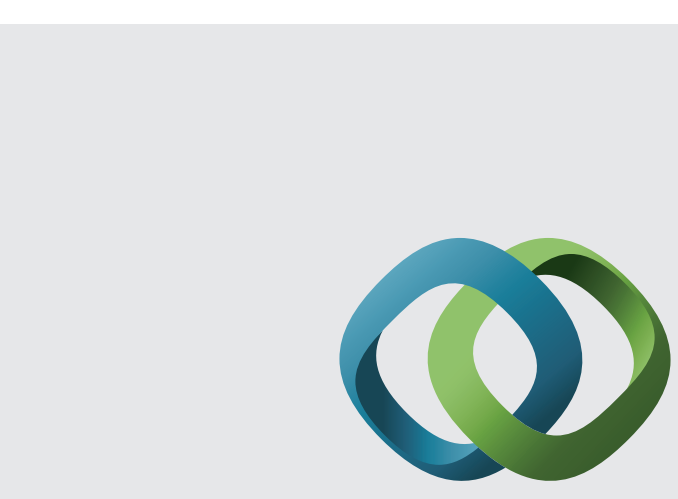

\section{Hindawi}

Submit your manuscripts at

http://www.hindawi.com
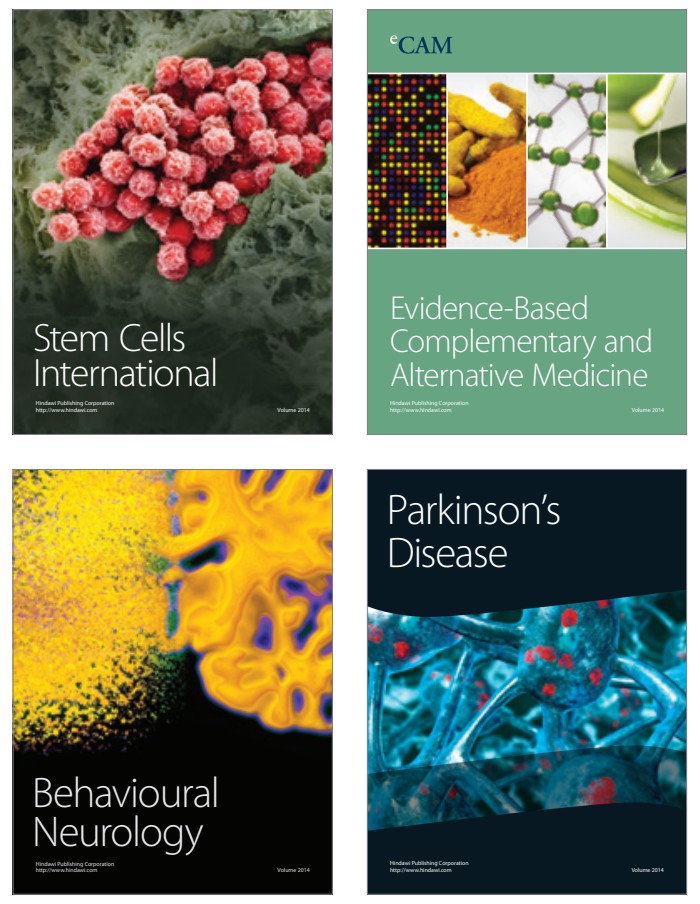
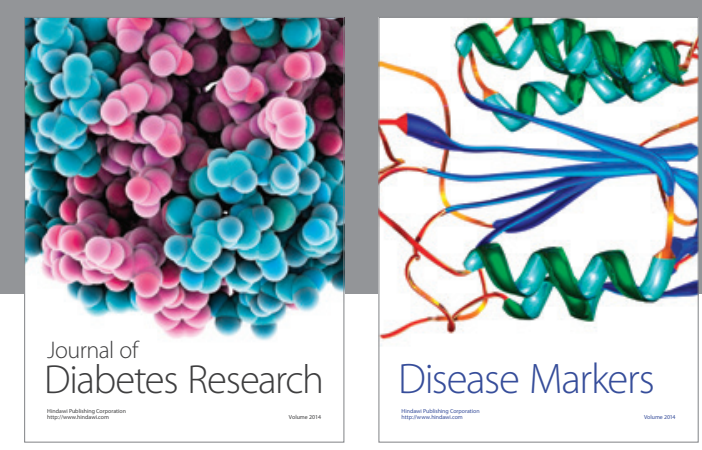

Disease Markers
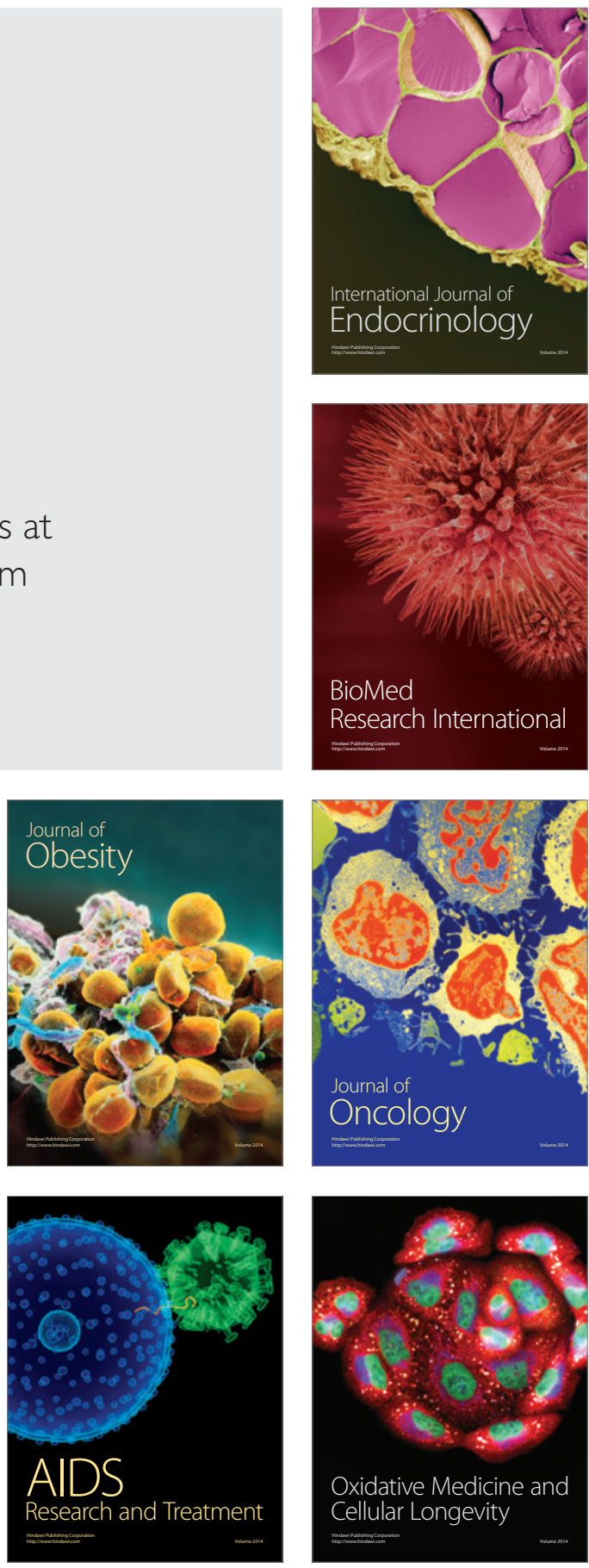